\title{
Comparison of lifestyles of young women with and without primary dysmenorrhea
}

\author{
Dina Abadi Bavil ${ }^{1}$, Mahrokh Dolatian², Zohreh Mahmoodi ${ }^{3,4}$, Alireza Akbarzadeh Baghban ${ }^{5}$
}

${ }^{1}$ Department of Midwifery, International Branch, Shahid Beheshti University of Medical Sciences, Tehran, Iran

${ }^{2}$ Assistant Professor, Department of Midwifery and Reproductive Health, School of Nursing and Midwifery, Shahid Beheshti University of Medical Sciences, Tehran, Iran

${ }^{3}$ Assistant Professor of Social Determinant of Health Research Center, Alborz University of Medical Sciences, Karaj, Iran

${ }^{4}$ Assistant Professor of Nursing \& Midwifery faculty, Alborz University of Medical Sciences, Karaj, Iran

${ }^{5} \mathrm{Ph} . \mathrm{D}$ in Biostatistics, Associate Professor, Proteomics Research Center, Department of Basic Sciences, School of Rehabilitation Sciences, Shahid Beheshti University of Medical Sciences, Tehran, Iran

\section{Type of article: Original}

\begin{abstract}
Introduction: Dysmenorrhea is one of the most common gynecologic disorders that affects women's quality of life and social activities. Lifestyle, eating behaviors, and general health are essential to the management of menstrual symptoms. This study was conducted to examine the relationship between lifestyle and primary dysmenorrhea in students at Sari University of Medical Sciences in 2015 in order to facilitate the performance of lifestyle-improving interventions among young women.

Methods: This study was conducted on 250 students with and without primary dysmenorrhea at Sari University of Medical Sciences in 2015. Data were collected using personal-social and lifestyle questionnaires (addressing nutrition, physical activity, stress, social relationships, improper health behaviors, and self-care). The data were analyzed by SPSS software, version 18, using the independent-samples t-test, the chi-squared test, and logistic regression analysis.

Results: Given the scores obtained on the lifestyle questionnaire, significant differences were observed between the groups with and without dysmenorrhea in terms of eating behavior $(\mathrm{p}=0.008)$, physical activity $(\mathrm{p}=0.011)$, stress $(\mathrm{p}=0.041)$, and social relationships $(\mathrm{p}=0.000)$. No differences were observed in terms of self-care $(\mathrm{p}=0.115)$ and smoking, drinking, and drug use $(\mathrm{p}=0.355)$. According to the logistic regression analysis, age $(\mathrm{OR}=1.208$, $\mathrm{p}=0.014)$, physical activity $(\mathrm{OR}=1.008, \mathrm{p}=0.040)$ and social relationship $(\mathrm{OR}=0.952, \mathrm{p}=0.002)$ were different in the two groups, but there was no statistical differences in their eating behavior, self-care, and stress.

Conclusion: To prevent and reduce the incidence of primary dysmenorrhea, knowledge and awareness should be raised in young women through proper lifestyle education and health promotion measures.

Keywords: dysmenorrhea, lifestyle, nutrition, physical activity, stress, social relationships, improper health behaviors
\end{abstract}

\section{Introduction}

Primary dysmenorrhea is menstrual pain with no pelvic pathology that often occurs 1-2 years after menarche, when the ovulation cycles are fully established (1). The overall prevalence of primary dysmenorrhea is between $60 \%$ and $90 \%$ among adolescent girls, and it decreases with age (2). In the U.S., dysmenorrhea is responsible for the loss of 600 million work hours and two million dollars each year (3). Primary dysmenorrhea is caused by increased or unbalanced production of endometrial prostanoid during menstruation. Prostaglandins increase uterine tone and contractions and cause pain. There are various medicinal and non-medicinal methods for the mitigation or

\section{Corresponding author:}

Assistant Professor Dr. Mahrokh Dolatian, Department of Midwifery and Reproductive Health, School of Nursing and Midwifery, Shahid Beheshti University of Medical Sciences, Tehran, Iran.

Tel: +98.2188202517, Fax: +98.2188202517, E-mail: mhdolatian@gmail.com

Received: December 16, 2015, Accepted: February 06, 2016, Published: March 2016

iThenticate screening: February 07, 2016, English editing: March 02, 2016, Quality control: March 08, 2016

(C) 2016 The Authors. This is an open access article under the terms of the Creative Commons Attribution-NonCommercialNoDerivs License, which permits use and distribution in any medium, provided the original work is properly cited, the use is non-commercial and no modifications or adaptations are made. 
elimination of this problem (1). The non-medicinal methods used to control primary dysmenorrhea include lifestyle and dietary pattern changes, such as reducing salt intake and reducing the consumption of animal fat, increasing the intake of complex carbohydrates and fibers, increasing physical activity, reducing stressors, and providing psychological support (4). Lifestyle, nutrition, and general health are essential factors in the management of menstrual symptoms (5). Recent studies have shown that lifestyle can be effective in causing stress and anxiety and creating mental pressures (6) that exacerbate dysmenorrhea (7). Lifestyle includes controllable and changeable behaviors that can affect the individual's health either positively or negatively (8). McDonald proposed six dimensions for lifestyle, including nutrition, physical activity, stress, self-care, social relationships, and improper health behaviors (9). According to various studies, the factors that affect primary dysmenorrhea include nutrition habits (7), aerobic exercise (10), feeling energized and refreshed upon waking up in the morning, having negative beliefs and attitudes toward menstruation, emotional and psychological responses (11), economic status (12), and exposure to cigarette smoke (13). Another study found no relationships between dysmenorrhea and life factors, such as exposure to cigarette smoke, smoking, drinking, exercise, and perceived stress or occupational factors, such as work stress (14). Given the prevalence of dysmenorrhea and its significant effects on the personal and social quality of life and the public appreciation of new lifestyle trends, finding a method of pain management that poses no sideeffects and that can replace medicinal methods has always been the main objective of researchers in this field. Some studies conducted on this subject have failed to produce suitable results. Therefore, we conducted this study to examine the relationship between lifestyle and primary dysmenorrhea in female students in order to facilitate lifestyle-improving interventions among young women.

\section{Material and Methods}

This descriptive-comparative study was conducted on 250 students at Sari University of Medical Sciences in 2015. Sampling was conducted between late August and late November 2015. A total of 125 students with primary dysmenorrhea and another 125 without primary dysmenorrhea were non-randomly assigned to each study group through convenience sampling. The study inclusion criteria consisted of being single, age in the 18-26 range, having primary dysmenorrhea with a moderate to severe degree of pain based on the McGill pain index (scores of 4 to 10) or having no pain (scores of 0 to 3), suffering from no known chronic diseases, such as diabetes, high blood pressure, underlying cardiac diseases, or infectious diseases, having no self-reported symptoms, such as vaginal burning, itching, or abnormal excretion, and having no history of gynecologic surgeries. Data were collected using personal-social and lifestyle questionnaires, the McGill pain index, and meter. The personal-social questionnaire contained sections on personal details, menstruation history, obstetric history, and socioeconomic status. The lifestyle questionnaire contained 82 items in six domains, including nutrition, physical activity, social relationships, perceived stress, self-care, and improper health behaviors. The nutrition style questionnaire contained 16 items scored on a 4-point Likert-type scale with a total score ranging from 16 to 64 . Overall nutrition scores of less than $33.3 \%$ indicated poor nutritional status, between $33.3 \%$ and $66.6 \%$ indicated moderately good nutrition, and greater than $66.6 \%$ indicated good nutritional status. The nutrition style questionnaire used was designed and psychometrically assessed by Mahmoodi et al., and the validity and reliability of the questionnaire also were confirmed with a Pearson correlation coefficient of $97 \%$ and a Cronbach's alpha value of $76 \%$ (15).

The International Physical Activity Questionnaire (IPAQ) (16) was used to assess the physical dimension; this questionnaire was developed in 1998 by the World Health Organization (WHO) and the Centers for Disease Control and Prevention (CDC) for individuals in the age range of 15 to 69. In this study, we used the long form of the IPAQ, which contains 27 items and reports physical activity results MET=Metabolic Equivalent Test (MET/Minute) per week and divides its respondents into three groups, i.e., a low-activity group (less than $600 \mathrm{Met}$ ), a moderate-activity group (600 to $3000 \mathrm{Met}$ ), and a high-activity group (more than $3000 \mathrm{Met}$ ). The IPAQ is a standard global scale with a validity that has been confirmed in previous studies through the measurement of the validity of its content $(17,18)$. Hazavehei et al. confirmed the reliability of the IPAQ with a Cronbach's alpha value of 0.8 (19). The social relationships questionnaire contained 10 items on both domestic and social relationships, and they were scored based on a 5-point Likert-type scale, where 1 was the most unfavorable, and 5 was the most favorable score. Overall scores of less than $33.3 \%$ indicated unfavorable social relationships, between $33.3 \%$ and $66.6 \%$ indicated relatively favorable social relationships, and higher than $66.6 \%$ indicated favorable social relationships. The social relationship questionnaire that we used was designed and psychometrically assessed by Mahmoodi et al.; the reliability of the questionnaire was confirmed with a Cronbach's alpha value of 0.752 (15). Cohen's Perceived Stress Scale was used to measure general stress perceived during the last month, and it assessed the individual's general thoughts and feelings about recent stressful experiences and mental pressures and the means of controlling these feelings and 
coming to terms with them. The present study used the 14-item version of the scale, where seven negative items indicated an inability to cope with stress, and seven positive items indicated that the respondent was well-adapted to stressors. The responses were scored based on a 5-point Likert-type scale from never given a score of 1 to very often a score of 4 (20), and with the lowest score being 0 and the highest being 56. Overall scores of less than 33.3\% indicated a low level of stress, between $33.3 \%$ and $66.6 \%$ indicated a moderate level of stress, and higher than $66.6 \%$ indicated a high level of stress. The reliability of Cohen's Perceived Stress Scale was confirmed in three studies using the internal consistency method and with a Cronbach's alpha value calculated as 0.84 to 0.86 (21).

The self-care questionnaire contained seven items scored based on a 4-point Likert-type scale, with scores ranging from 7 to 28 . Overall scores of less than $33.3 \%$ indicated a poor health accountability, between $33.3 \%$ and $66.6 \%$ indicated a moderate health accountability, and higher than $66.6 \%$ indicated a high health accountability. The health accountability questionnaire used in this study was derived from the questionnaire designed and psychometrically assessed by Khosrorad; the reliability of this questionnaire was confirmed with a Pearson correlation coefficient of 0.97 and a Cronbach's alpha value of 0.76 (22). A questionnaire designed and psychometrically assessed by Khosrorad et al. was used to assess improper health behaviors; the validity and reliability of this questionnaire were confirmed with a Pearson correlation coefficient of 0.98 and a Cronbach's alpha value of 0.69 (22). The McGill pain scale is the most common visual analog scale with many applications in different studies and with a validity and reliability that already have been confirmed (23). The reliability of the weighing scale was determined by weighing a 2-kg control weight, and then, according to the manufacturer's instructions, the scale was calibrated with the same standard weight after it was weighed 10 times. The reliability of the meter was determined using a non-flexible metal meter. The data were analyzed using SPSS software, version 18, using descriptive and analytical statistics, such as mean, standard deviation, the independent-samples t-test, the chi-squared test, and logistic regression analysis.

\section{Results}

The study was conducted on 250 students. According to the results obtained, the two groups were significantly different in terms of age $(\mathrm{p}=0.001)$ and degree of education $(\mathrm{p}=0.011)$, but not in terms of BMI $(\mathrm{p}=0.296)$, age at menarche $(p=0.0374)$, duration of menstruation $(p=0.54)$, menstrual cycle $(p=0.54)$, diet $(p=0.233)$, and socioeconomic status $(\mathrm{p}=0.346)$; that is to say, the groups were matched in these areas (Table 1). Based on the scores obtained on the lifestyle questionnaire, the two groups were significantly different in terms of nutrition style $(\mathrm{p}=0.008)$, physical activity $(\mathrm{p}=0.011)$, stress $(\mathrm{p}=0.041)$, and social relationships $(\mathrm{p}=0.000)$, but not in terms of selfcare $(\mathrm{p}=0.115)$ or improper health behaviors $(\mathrm{p}=0.355)$ (Table 2$)$.

Table 1. Demographic and midwifery characteristics of young women with and without primary dysmenorrhea

\begin{tabular}{|l|l|l|l|}
\hline Variables & Dysmenorrhea $($ Mean \pm SD) & Without dysmenorrhea $($ Mean \pm SD) & p-value \\
\hline Age $($ year $)$ & $21.4 \pm 2.09$ & $21.22 \pm 2.13$ & 0.001 \\
\hline BMI & $22.37 \pm 3.50$ & $21.92 \pm 3.34$ & 0.296 \\
\hline Menarche age & $13.39 \pm 1.39$ & $13.24 \pm 1.30$ & 0.374 \\
\hline Menstrual cycle & $21.75 \pm 2.42$ & $22.54 \pm 3.88$ & 0.054 \\
\hline Duration of menstruation & $6.37 \pm 1.32$ & $6.27 \pm 1.13$ & 0.540 \\
\hline Socioeconomic status & $4.24 \pm 0.904$ & $4.13 \pm 0.877$ & 0.346 \\
\hline
\end{tabular}

Table 2. Frequency Distribution and comparison of lifestyles in young women with and without primary dysmenorrhea

\begin{tabular}{|l|l|l|l|}
\hline Lifestyles Item & Dysmenorrhea & Without dysmenorrhea & p-value \\
\hline Eating behaviors (Mean \pm SD) & $57.91 \pm 10.92$ & $61.68 \pm 11.33$ & 0.008 \\
\hline Physical Activity $(M E T)(M e a n+$ SD) & $91.97 \pm 53.03$ & $77.77 \pm 32.16$ & 0.011 \\
\hline Perceived Stress (Mean \pm SD) & $46.51 \pm 12.24$ & $43.32 \pm 12.22$ & 0.041 \\
\hline Social relationships $(M e a n \pm$ SD) & $69.68 \pm 7.52$ & $74.08 \pm 10.01$ & 0.000 \\
\hline Self-Care (Mean \pm SD) & $52.26 \pm 18.12$ & $56.19 \pm 21$ & 0.115 \\
\hline Improper health behaviors; $n(\%)$ & $7(5.6)$ & $4(3.2)$ & 0.355 \\
\cline { 2 - 4 } & $118(94.4)$ & $121(96.8)$ & \\
\hline
\end{tabular}

The logistic regression analysis showed no significant differences between the two groups in terms of nutrition style, self-care, and stress. The results showed that, for each unit of increase in the social relationships score, the odds of 
experiencing dysmenorrhea were reduced by 0.05 . In other words, it is less likely for individuals with more favorable social relationships to experience dysmenorrhea. Moreover, an increase of one unit in the physical activity score reduced the odds of experiencing dysmenorrhea by 0.01 ; in other words, more physically active women are less likely to experience dysmenorrhea. The odds of experiencing dysmenorrhea are reduced by 0.18 with age; in other words, as they get older, women become less likely to suffer from this condition (Table 3).

Table 3. Logistic regression analysis of effective factors on primary dysmenorrhea

\begin{tabular}{|l|l|l|l|l|}
\hline Lifestyle dimension & Exp $(\mathrm{B})=\mathrm{OR}$ & $\mathrm{CI}(\% 95)$ & $\mathrm{p}$-value & $\mathrm{B}$ \\
\hline Age & 1.208 & $1.014-1.404$ & 0.014 & 0.189 \\
\hline Education & 1.318 & $0.837-2.076$ & 0.233 & 0.276 \\
\hline Eating behaviors & 0.977 & $0.951-1.004$ & 0.089 & -0.024 \\
\hline Physical Activity & 1.008 & $1.000-1.016$ & 0.040 & 0.008 \\
\hline Perceived Stress & 1.007 & $0.983-1.032$ & 0.556 & 0.007 \\
\hline Social relationships & 0.952 & $0.922-0.983$ & 0.002 & -0.049 \\
\hline Self-Care & 0.994 & $0.978-1.009$ & 0.410 & -0.006 \\
\hline
\end{tabular}

\section{Discussion}

In this study, we found a relationship between dysmenorrhea and nutrition, physical activity, stress, and social relationships in the two groups. A favorable nutritional status reduced the severity of dysmenorrhea. Several studies have confirmed the role of vasopressin in increased myometrial activity and reduced local uterine blood flow. Vasopressin is a hormone that increases with the stimulation of the supraoptic nuclei due to the resultant increased osmolality and reduced volume of the blood (24). Ekstrom et al. showed that the infusion of hypertonic saline during menstruation increases vasopressin and oxytocin and, thereby, the severity of dysmenorrhea (25). Foods that contain high levels of magnesium can reduce the severity of dysmenorrhea by reducing the synthesis of prostaglandin and reducing muscle and microvascular spasms (26). A high-fiber diet can increase the sex hormone-binding globulins, thereby reducing the synthesis of prostaglandin, which is the main causative factor of dysmenorrhea (27). Studies have confirmed the role of arachidonic acid (contained in animal fats, especially meat and dairy) in the synthesis of prostaglandin (7). Concerning the daily consumption of the four major food groups, research has shown that a diet high in fish, eggs, vegetables, and fruits is associated with a low prevalence of dysmenorrhea (28). Eliminating salty foods also helps reduce the incidence of dysmenorrhea (29). Moreover, eating breakfast (30), nuts (31), and pure honey $(32,33)$ helps reduce the incidence of dysmenorrhea. Exercise acts as a non-specific analgesic by improving pelvic blood circulation and stimulating the release of beta-endorphins (34). Exercise prevents and abates dysmenorrhea by helping to reduce mental pressure, to improve mood, and to reduce the percentage of body fat, which is crucial given that obesity is associated with a high prevalence of dysmenorrhea (35). Salehi et al. found significant differences between their case and control groups in terms of the intensity and duration of pain after eight weeks of Pilates exercise (36). Brisk walking for 30 minutes a day during the first three days of menstruation reduces the severity of primary dysmenorrhea and menstrual pain. The prevalence of dysmenorrhea was lower in athletes who had three regular sessions of exercise per week than in non-athletes (37). Exercise has the greatest effect on the prevention of dysmenorrhea when it is ongoing and when it begins before menarche (35). In this study, we found that the prevalence of dysmenorrhea was lower in women who were more physically active and also that regular exercise reduced the levels of stress in women, thereby improving the circulation of blood circulation and increasing their endorphins and neurotransmitters (38). Educational and counseling measures should be implemented to encourage women to exercise more.

In this study, we found moderate and high levels of stress to be more prevalent in the group with dysmenorrhea than in the group without this condition. In similar studies by Kurdi et al. and Wong et al. (39), a positive and significant correlation was obtained between occupational stress and the severity of dysmenorrhea. Given that primary dysmenorrhea is related significantly to anxiety and depression, psychological support during the treatment of dysmenorrhea is essential (40). Although psychological factors rarely appear to cause dysmenorrhea in and by themselves, they may still be considered a definitive factor in the exacerbation of the severity of dysmenorrhea and menstrual pain (41). In contrast, one study reported the lack of a relationship between dysmenorrhea and life factors, such as perceived stress and occupational stress (14). The disparity of results may be attributed to the type of questionnaires used and the matching of the groups in terms of stress levels. The present study showed significantly more favorable social relationships in the group without dysmenorrhea than in the group with dysmenorrhea. The 
support received through social relationships affects the individual's mental and physical health in the emotional, cognitive, and behavioral dimensions (42). A study conducted on the effect of psycho-social factors on dysmenorrhea found that a greater percentage of women who had poor social support, occupational stress, and poor job security had dysmenorrhea (43).

In this study we did not find any significant differences between the two groups in terms of smoking and drinking. However, a study conducted by Pan et al. found a significant relationship between smoking at home and at work and menstrual disorders and dysmenorrhea (44). The prevalence of dysmenorrhea was higher in women smokers (41), which was likely due to the nicotine content of cigarettes, which causes vasoconstriction and the resultant hypoxia then contributes to myometrial contraction (45). Speroff also had a similar opinion (2). The relationship between alcohol and dysmenorrhea is controversial; however, according to many studies, the daily intake of alcohol is a risk factor for dysmenorrhea (28). Alcohol destroys food reserves, alters the metabolism of carbohydrates, and causes muscular cramps and spasm. The ability of the liver to metabolize hormones also is impaired by alcohol, leading to increased estrogen levels, increased liquid content, salt retention, and increased menstrual bleeding (46). Life factors, such as exposure to smoke, smoking, and drinking showed no relationships with dysmenorrhea (14). The disparity of the findings between the studies may be attributed to various factors, such as age, different cultures in different cities and countries, and sample size. Based on the results of this study, we could not conclude that there were definite relationships due to the small number of smokers and drinkers in the two groups.

No significant differences were observed between the two groups in terms of their level of accountability. Age and menstruation education had direct and indirect effects on self-care behaviors. Self-care behaviors were directly linked to the parents' degree of education, the severity of pain, and the use of medications in those who suffered from dysmenorrhea. Learning about the factors that affect self-care behaviors in adolescent girls is effective in performing self-care promoting interventions and thus reducing the negative effects of the disease (47). Kabirian et al. found no statistically significant differences between self-care behaviors and lifestyle in women with dysmenorrhea (48). There was a statistically significant difference between the two groups in terms of age. The prevalence of primary dysmenorrhea decreased with age. Dysmenorrhea is more common between the ages of 20 and 24, and it becomes progressively less common after age 24 (49). No significant differences were observed between the two groups in terms of BMI. Heidari et al. also found no significant differences between their study groups in terms of BMI, height, weight, and the waist-to-hip ratio (WHR) (50).

A significant positive relationship was observed between a high BMI and dysmenorrhea. The disparity of results between the present study and a study conducted by Harlow may be attributed to how BMI is affected by various factors, such as race, age, and gender and how it is not an appropriate obesity index, especially in athletes who have high BMIs (37). No significant differences were observed between the two groups in terms of age at menarche, duration of menstruation, and menstrual cycle. However, Speroff found a significant relationship between age at menarche and the severity of primary dysmenorrhea. Long menstrual cycles (51), heavy bleeding (49), and menstruation lasting longer than seven days (52) increase the risk of primary dysmenorrhea. However, Jang et al. believed that dysmenorrhea was not related to the duration of the menstrual cycle (53). In this study, the groups were matched for confounding factors and, thus, no differences were observed between them in terms of menstruation history. Due to time constraints, it was not possible to check additional women. Note that we did not calculate the unhealthy behavior score because there were not many of the women who smoked and consumed alcohol.

\section{Conclusions}

This research showed that an appropriate lifestyle can reduce the severity of dysmenorrhea, hence, with a suitable eating behavior, regular physical activity, self-care, high level social relationships, and reduction in stress levels in women, the occurrence of the dysmenorrhea can be reduced. With attention to the negative effects of dysmenorrhea on the quality of life, we must take steps to increase the female population's awareness of dysmenorrhea and the appropriate lifestyle to reduce its occurrence and effects.

\section{Acknowledgments:}

This research was derived from an M.S. thesis in the field of midwifery. We appreciate the cooperation of the honorable Research Deputies at the University of Shahid Beheshti and Sari University as well as all of the female students who participated. 


\section{Conflict of Interest:}

There is no conflict of interest to be declared.

\section{Authors' contributions:}

All authors contributed to this project and article equally. All authors read and approved the final manuscript.

\section{References}

1) Novak E, Berek JS. Berek \& Novak's gynecology: Lippincott Williams \& Wilkins; 2012.

2) Speroff L, Fritz MA. Clinical gynecologic endocrinology and infertility: lippincott Williams \& wilkins; 2011.

3) Weissman AM, Hartz AJ, Hansen MD, Johnson SR. The natural history of primary dysmenorrhoea: a longitudinal study. BJOG. 2004; 111(4): 345-52. PMID: 15008771.

4) O'Brien PS, Abukhalil I. Randomized controlled trial of the management of premenstrual syndrome and premenstrual mastalgia using luteal phase-only danazol. Am J Obstet Gynecol. 1999; 180(1): 18-23. PMID: 9914571.

5) Bianco V, Cestari A, Casati D, Cipriani S, Radici G, Valente I. Premenstrual syndrome and beyond: lifestyle, nutrition, and personal facts. Minerva ginecologica. Minerva Ginecol. 2014; 66(4): 365-75. PMID: 25020055.

6) Samiei Siboni F, Alimoradi Z, Sadegi T. Impact of corrective life style educational program on controlling stress, anxiety, and depression in hypertensives. Journal of Birjand University of Medical Sciences. 2013; 19(6): 1-9.

7) Molazem Z, Alhani F, Anooshe M, Vagharseyyedin SA. Epidemiology of dysmenorrhea with dietary habits and exercise. Zahedan Journal of Research in Medical Sciences. 2011; 13(3): 41-5.

8) Sharma R, Biedenharn KR, Fedor JM, Agarwal A. Lifestyle factors and reproductive health: taking control of your fertility. Reprod Biol Endocrinol. 2013; 11(66): 1-15. doi: 10.1186/1477-7827-11-66, PMID: 23870423.

9) Mcdonald S, Thompson C. Women's health. Elsevier. 2005; Australia: 90-121.

10) Mohammadi B, Azamian Jazi A, Fathollahi Shourabeh F. The Effect of Aerobic Exercise Training and Detraining on Some of the Menstrual Disorders in Non-athlete Students in Lorestan Universities. The Horizon of Medical Sciences. 2012; 18(2): 5-12.

11) Nazarpour S. Study of factors of influencing on severity of primary dysmenorrhea in students of nursing and midwifery of governmental universities under the supervision of ministry of health, treatment and medical education in Tehran. Quarterly journal of woman \& hygiene. 2010; 1(2): 109-25.

12) Akhavanakbary P, Ahangar DS. Dysmenorrhea frequency and severity and its related factors in students of ardabil university of medical science in 1388. Journal Of Health And Hygiene. 2011; 1(3): 41-7. (Persian)

13) Chen C, Cho S-I, Damokosh AI, Chen D, Li G, Wang X, et al. Prospective study of exposure to environmental tobacco smoke and dysmenorrhea. Environ Health Perspect. 2000; 108(11): 1019. doi: 10.1289/ehp.001081019, PMID: 11102290, PMCID: PMC1240156.

14) Chung FF, Yao Cc, Wan GH. The associations between menstrual function and life style/working conditions among nurses in Taiwan. J Occup Health. 2005; 47(2): 149-56, PMID: 15824480.

15) Mahmoodi Z, Karimlou M, Sajjadi H, Dejman M, Vameghi M. Development of Mother's Lifestyle Scale during Pregnancy with an Approach to Social Determinants of Health. Glob J Health Sci. 2013; 5(3): 208. doi: 10.5539/gjhs.v5n3p208, PMID: 23618491.

16) Committee IR. Guidelines for data processing and analysis of the International Physical Activity Questionnaire (IPAQ). Consultado em. 2005; 20.

17) Dinger M, Oman R, Taylor E, Vesely S, Able J. Stability and convergent validity of the Physical Activity Scale for the Elderly (PASE). J Sports Med Phys Fitness. 2004; 44(2): 186-92. PMID: 15470317.

18) Kurtze N, Rangul V, Hustvedt B-E, Flanders WD. Reliability and validity of self-reported physical activity in the Nord-Trøndelag Health Study: HUNT 1. Scand J Public Health. 2008; 36(1): 52-61. doi: 10.1177/1403494807085373, PMID: 18426785.

19) Hazavehei SMM, Asadi Z, Hassanzadeh A, Shekarchizadeh P. Comparing the effect of two methods of presenting physical education $\Pi$ course on the attitudes and practices of female Students towards regular physical activity in Isfahan University of Medical Sciences. Iranian Journal of Medical Education. 2008; 8(1): 121-31. 
20) Leung DY, Lam TH, Chan SS. Three versions of Perceived Stress Scale: validation in a sample of Chinese cardiac patients who smoke. BMC public health. 2010; 10(1): 513. doi: 10.1186/1471-2458-10-513, PMID: 20735860 , PMCID: PMC2939644.

21) Cohen S, Kamarck T, Mermelstein R. A global measure of perceived stress. J Health Soc Behav. 1983: 385-96. PMID: 6668417.

22) Khosrorad T, Dolatian M, Riazi H, Mahmoodi Z, Alavimajd H, Shahsavari S, et al. Comparison of lifestyle in fertile and infertile couples in Kermanshah during 2013. Iran J Reprod Med. 2015; 13(9): 549-56. PMID: 26568759, PMCID: PMC4637122.

23) Wall PD, Jones M. Defeating pain: The war against a silent epidemic: Springer; 2013.

24) Bossmar T, Rasmussen T, Åkerlund M. Effect of the non-peptide, vasopressin V1a receptor antagonist, SR 49059 and its enantiomer, SR 49770, on isolated human myometrium. Acta Obstet Gynecol Scand. 1996; 75(6): 516-9. PMID: 8693925.

25) Eksrtrom P, Akerlund M, Forsling M, Kindahl H, Laudanski T, Mrugacz G. Stimulation of vasopressin release in women with primary dysmenorrhoea and after oral contraceptive treatment-effect on uterine contractility. Br J Obstet Gynaecol. 1992; 99(8): 680-4. PMID: 1390475.

26) Hudson T. Using nutrition to relieve primary dysmenorrhea. Alternative \& Complementary Therapies. 2007; 13(3): 125-8. doi: 10.1089/act.2007.13303.

27) Barnard ND, Scialli AR, Hurlock D, Bertron P. Diet and Sex - Hormone Binding Globulin, Dysmenorrhea, and Premenstrual Symptoms. Obstet Gynecol. 2000; 95(2): 245-50. PMID: 10674588.

28) Balbi C, Musone R, Menditto A, Di Prisco L, Cassese E, D'Ajello M, et al. Influence of menstrual factors and dietary habits on menstrual pain in adolescence age. Eur J Obstet Gynecol Reprod Biol. 2000; 91(2): 143-8. PMID: 10869786.

29) Durain D. Primary dysmenorrhea: assessment and management update. J Midwifery Womens Health. 2004; 49(6): 520-8. PMID: 15544981.

30) Fjerbaek A, Knudsen UB. Endometriosis, dysmenorrhea and diet-What is the evidence. Eur J Obstet Gynecol Reprod Biol. 2007; 132(2): 140-7. PMID: 17210218.

31) Woolven L. The Smart Woman's Guide to PMS and Pain-Free Periods: John Wiley \& Sons; 2010.

32) White Jr JW. Detection of honey adulteration by carbohydrage analysis. J Assoc Off Anal Chem. 1980; 63(1): 11-8. PMID: 7380780.

33) Bertelli D, Lolli M, Papotti G, Bortolotti L, Serra G, Plessi M. Detection of honey adulteration by sugar syrups using one-dimensional and two-dimensional high-resolution nuclear magnetic resonance. J Agric Food Chem. 2010; 58(15): 8495-501. doi: 10.1021/jf101460t, PMID: 20681637.

34) Proctor M, Farquhar C. Diagnosis and management of dysmenorrhoea. BMJ. 2006; 332(7550): 1134-8. PMID: 16690671, PMCID: PMC1459624.

35) Sargolzayi M, Keykhayi N. dyssmenorhea and exercise in women. Journal of medical science. 1377; 3(1112): $52-5$.

36) Salehi F, Marefati H, Mehrabian H, Sharifi H. Effect of pilates exercise on primary dysmenorrhea. Research in Rehabilitation Sciences. 2012; 1(1): 248-53.

37) Ezbarami S, Mirzaei B, Esfarjani F. Comparison the prevalence and severity of dysmenorrhea among athletes and non-athletes and its relation with body composition. Arak Medical University Journal. 2014; 16(11): 80-8.

38) Mayo JL. A healthy menstrual cycle. Clin Nutr Insights. 1997; 5(9): 1-8.

39) Wang L, Wang $X$, Wang W, Chen $C$, Ronnennberg A, Guang W, et al. Stress and dysmenorrhoea: a population based prospective study. Occup Environ Med . 2004; 61(12): 1021-6. PMID: 15550609.

40) Gagua T, Tkeshelashvili B, Gagua D, Mchedlishvili N. Assessment of anxiety and depression in adolescents with primary dysmenorrhea: a case-control study. J Pediatr Adolesc Gynecol. 2013; 26(6): 3504. doi: 10.1016/j.jpag.2013.06.018, PMID: 24075089.

41) Howard FM. Chronic pelvic pain. Obstet Gynecol. 2003; 101(3): 594-611.

42) Cohen S. Social relationships and health. Am Psychol. 2004; 59(8): 676. PMID: 15554821.

43) László KD, GyÖrffy Z, Adam S, Csoboth C, Kopp MS. Work-related stress factors and menstrual pain: a nation-wide representative survey. J Psychosom Obstet Gynaecol. 2008; 29(2): 133-8. doi: 10.1080/01674820701804423, PMID: 18484442.

44) Pan X, Ding H, Han L, Wang L. [Effects of passive smoking on menstrual function of perimarital women]. Wei Sheng Yan Jiu. 1999; 28(1): 23-5. PMID: 12712741.

45) Brito SA, Marques CCC, Alves DS, da Silva Alexandre AC. Prevalence of dysmenorrhea in undergraduate health courses at an institution of higher education. JNUOL. 2012; 6(6): 1386-94. doi: 10.5205/01012007. 
46) Hudson T. Natural progesterone: Clinical indications in women's health. Female Patient. 2001; $26(4): 43-8$.

47) Crezee I, Atkinson D, Pask R, Au P, Wong S, editors. Teaching interpreters selfcare. 2015: Conference of Interpreter Trainers (CIT).

48) Kabirian M, Abedian Z, Mazlom SR, Mahram B. Self-management in primary dysmenorrhea: toward evidence-based education. Life Sci J. 2011; 8(2): 13-8.

49) Smith RP. Netter's obstetrics and gynecology: Elsevier Health Sciences; 2008.

50) Harlow SD, Park M. A longitudinal study of risk factors for the occurrence, duration and severity of menstrual cramps in a cohort of college women. Br J Obstet Gynaecol. 1996; 103(11): 1134-42. doi: 10.1111/j.1471-0528.1996.tb09597.x, PMID: 8917003.

51) Haidari F, Akrami A, Sarhadi M, Mohammad Shahi M. Prevalence and severity of primary dysmenorrhea and its relation to anthropometric parameters. Hayat. 2011; 17(1): 70-7.

52) Unsal A, Ayranci U, Tozun M, Arslan G, Calik E. Prevalence of dysmenorrhea and its effect on quality of life among a group of female university students. Ups J Med Sci. 2010; 115(2): 138-45. doi: 10.3109/03009730903457218, PMID: 20074018.

53) Chung YC, Chen HH, Yeh ML. Acupoint stimulation intervention for people with primary dysmenorrhea: systematic review and meta-analysis of randomized trials. Complement Ther Med. 2012; 20(5): 353-63. doi: 10.1016/j.ctim.2012.02.008, PMID: 2286365. 